\title{
COMPARISON OF CEPA (2-CHLOROETHYL PHOSPHONIC ACID) INDUCED RESPONSES IN JUVENILE EUCALYPTUS NITENS, E. GLOBULUS AND E. OBLIQUA: A HISTOCHEMICAL AND ANATOMICAL STUDY
}

by

\begin{abstract}
Alieta Eyles $^{1,2 *}$ \& Caroline Mohammed ${ }^{1,2,3}$
\end{abstract}
\section{SUMMARY}

Kino veins and/or pockets are a characteristic defect of some Eucalyptus species and have long been recognized as sources of degrade in eucalypt timber. In a comparative study, the course of both histochemical and anatomical responses of three juvenile Eucalyptus species (E. nitens, E. globulus and E. obliqua) to treatment with an ethylene-releasing compound, 2-chloroethyl phosphonic acid (CEPA), were examined. Kino veins were induced in both E. obliqua and E. globulus. The hormone treatment failed to induce kino vein formation in E. nitens. The traumatic parenchyma (that later differentiated into kino veins) was not always derived from the initials of the vascular cambium as reported in previous studies of E. globulus. Instead, the traumatic parenchyma appeared to be produced from the meristematic activity of the inner phloem parenchyma. In addition, kino veins found in 2- to 3-year-old E. globulus were mostly included in the phloem and not in the xylem as generally observed in mature E. globulus.

Key words: Kino vein development, 2-chloroethyl phosphonic acid, traumatic parenchyma, localization of proanthocyanidins.

\section{INTRODUCTION}

Eucalyptus globulus and E. nitens are widely planted in Tasmania for pulp and sawlog (Beadle \& Mohammed 1999). In intensively-managed E. globulus plantations, there exists a potential problem of sawlog downgrade due to kino vein incidence (Gerrand et al. 1997). Kino veins and/or pockets are a characteristic industrial defect of some Eucalyptus species arising from damaged cambial regions (Bamber 1985). Most authors agree that kino veins generally play a role in wound defence as a tree resistance mechanism by acting as a 'barrier zone' (Hillis 1987). A barrier zone is broadly defined

1) Co-operative Research Centre for Sustainable Production Forestry, GPO Box 252-12, Hobart, Tasmania 7001, Australia.

2) School of Agricultural Science, University of Tasmania, GPO Box 252-54, Hobart, Tasmania 7001, Australia.

3) CSIRO Forestry and Forest Products, GPO Box 252-12, Hobart, Tasmania 7001, Australia.

*) Author to whom correspondence should be addressed [E-mail: Alieta.Eyles@ ffp.csiro.au]. 
as a protective tissue, which forms in response to infection as well as to mechanical wounding (Tippett \& Shigo 1981) and is characterized by a great amount of axial parenchyma and few conducting elements (Torelli et al. 1994).

The plant hormone ethylene is well known to play a key role in the formation of tree exudates (Hillis 1975, 1987). The exogenous application of ethylene to induce or enhance secretion of tree exudates has been well documented, e.g. latex from Hevea species, gum from Prunus species and resin from Pinus species (Hillis 1987). Similarly, application of Ethrel onto bark has been used to induce kino veins in the seedlings of several juvenile Eucalyptus species (Dowden \& Foster 1973). Ethrel is a commercial preparation of 2-chloroethyl phosphonic acid (CEPA), an ethylene-releasing compound. The developmental anatomy and structure of kino veins induced by either mechanical or chemical wounding has been studied in detail in only a few eucalypt species, e.g. E. obliqua (Skene 1965) and E. radiata (Dowden \& Foster 1973). The developmental anatomy and structure of kino veins in E. nitens and E. globulus has not been previously studied. The present study reports the histochemical and anatomical responses of 2-3-year-old potted trees of three commercially important Eucalyptus species (E. globulus, E. obliqua and E. nitens) treated with CEPA.

\section{MATERIALS AND METHODS}

\section{Induction of kino veins with CEPA}

Six trees each of E. globulus, E. obliqua and E. nitens, 2 and 3 years of age and approximately $5-7 \mathrm{~cm}$ in diameter were used. Trees were grown outside in a commercial soil mix and subject to regular application of liquid fertilizer and daily watering. Each tree was injected with a total of $0.3 \mathrm{ml}$ of $1 \%$ CEPA aqueous solution (2-chloroethyl phosphonic acid, SIGMA) at 3 replicate points along the main stem (20, 40 and $60 \mathrm{~cm}$ above soil level). In addition, $0.3 \mathrm{ml}$ of distilled water was also injected in the same stem at $80 \mathrm{~cm}$ above soil level as a control. A fine needle (Luer Hub, 24G x $1 \mathrm{In}$, Aldrich) was inserted into the phloem until the needle tip encountered the much harder xylem tissue. The CEPA and the water were then applied in a number of small increments to allow the tissue to absorb the solution. The experiment commenced in late spring. Harvesting of $1 \mathrm{~cm}^{3}$ wood samples, that included the needle site, occurred after 7, 14, 21, 28, 35 and 42 days. The experiment was conducted in the late spring of 1999 and one year later.

\section{Light microscopy}

Wood samples were fixed in FAA (formaldehyde: acetic acid:50\% ethanol; $5: 5: 90$ ) for a minimum of $24 \mathrm{~h}$ at $4{ }^{\circ} \mathrm{C}$, then dehydrated with an ethanol series $(50 \%, 70 \%$, $95 \%, 3 \times 100 \%$ ), infiltrated in L. R. White acrylic resin (ProSciTech, Brisbane) and polymerized for $8-10 \mathrm{~h}$ at $60^{\circ} \mathrm{C}$. The embedded samples were sectioned at approximately $10-12 \mu \mathrm{m}$ thickness with a sledge microtome. Additional sections of 5-10 $\mu \mathrm{m}$ thickness were obtained with a rotary microtome (Leitz 1516) fitted with a glass knife. Transverse and longitudinal sections were dried onto glass slides, stained with a $1 \%$ aqueous solution of toluidine blue and permanently mounted in Cytoseal (Proscitech, 
Brisbane). Tissue structure and cell changes were noted. Photographs were taken with colour film (tungsten) on a Zeiss Axioskop photo-microscope fitted with a Zeiss MC 100 camera.

\section{Staining methods}

Cell wall histochemistry — Lignin presence was examined using the phloroglucinol-HCl test as described by Jensen (1962). Suberin (wall-bound lipid polymers) was stained with Sudan black B (Jensen 1962) in 70\% ethanol. In addition, suberin was detected with a Zeiss Axiovert fluorescence microscope using a mercury lamp. The autofluorescence of lignin was quenched with $1 \%$ phloroglucinol- $\mathrm{HCl}$ as outlined in Biggs (1984).

Localization of proanthocyanidins - Kino veins produce a red-brown aqueous solution of polyphenolic compounds called kino. The main constituents of kino are mostly polyphenolic compounds, in particular polymeric proanthocyanidins (syn. condensed tannins) (Hillis \& Yazaki 1975). A number of histochemical stains are commonly used for the localization of polyphenols, e.g. incubation with the nitroso reagent or the ferric chloride test (Jensen 1962). However, these methods are non-specific and selective staining of different tannins is not possible. In this study, two alternative methods were tested for the specific localization of proanthocyanidins within the plants.

a) Monomeric flavan-3-ols as well as the corresponding oligomeric proanthocyanidins were detected with $p$-dimethylaminocinnamaldehyde (DMACA) (modified from Gutmann 1993). The embedded sections were placed on glass slides, covered with the staining solution $(2 \mathrm{~mL}$ of $0.1 \%$ DMACA dissolved in $3 \mathrm{M}$ sulphuric acid in 1-butanol) and then heated for around $10 \mathrm{~s}$ on a hot plate. A green/blue-coloured product was observed in the presence of proanthocyanidins. This method provided good results and was less time consuming than the method outlined by Gutmann (1993).

b) Detection of hydrolyzable tannins was carried out with the Bradford proteinbinding dye, Coomassie brilliant blue G-250 (BBG-250). In a chemical assay, Kilkowski and Gross (1999) reported this dye to react specifically with hydrolyzable tannin standards to form intensively blue-coloured complexes. With this information in mind, a simple method was developed to localize the hydrolyzable tannins in situ with BBG-250. To effect this, the reactants were dissolved in water to avoid interference caused by organic solvents (as suggested by Kilkowski \& Gross 1999), applied to fresh sections for 10 minutes, and then rinsed with water.

\section{RESULTS AND DISCUSSION}

\section{Initial response to CEPA treatment}

In all three species studied, the initial response to the CEPA treatment involved 'swelling' of the ray parenchyma located within the vascular cambium. The ray parenchyma appeared to undergo anticlinal divisions giving rise to bi- to multi-seriate ray parenchyma (Fig. 1). After 'ray swell', the ray parenchyma in the mature xylem as well as in the adjacent healthy cambial zone proliferated extensively such that the ray cell derivatives completely filled the injection wound gap (Fig. 2). 

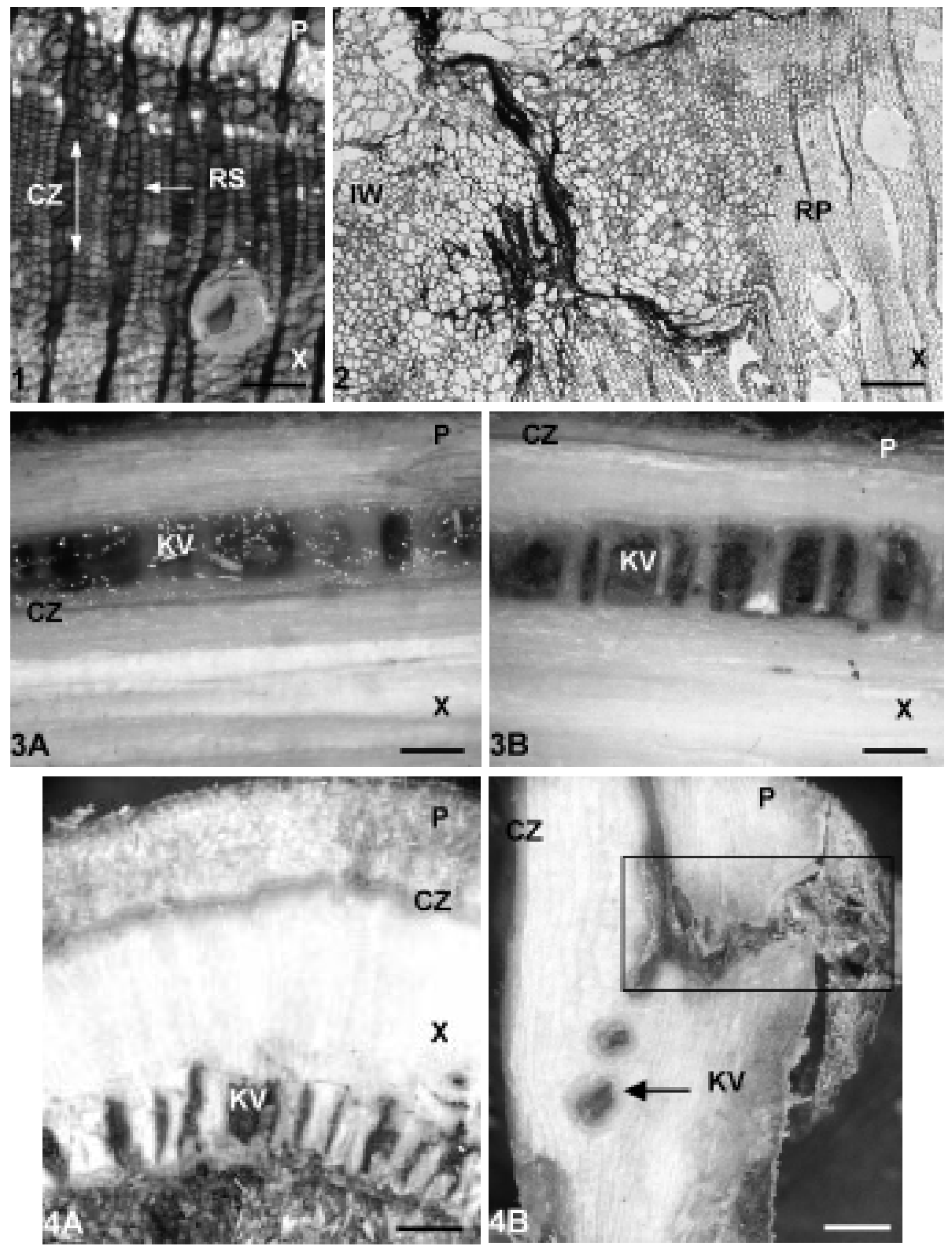

Fig. $1 \& 2$. Response of ray parenchyma to injection wound. - 1: Transverse section showing swelling of ray parenchyma located within the cambial zone (E. globulus). Scale bar $=75 \mu \mathrm{m}$. - 2: Transverse sections showing callus-like proliferation of ray cells (arrow) (E. obliqua). Scale bar $=100 \mu \mathrm{m}$. - Fig. 3. Radial longitudinal sections of kino vein development in the xylem of E. obliqua and E. globulus treated with CEPA. -A: 35 days post-induction (E. obliqua). - B: 45 days post-induction (E. globulus). Scale bars approximately $0.5 \mathrm{~cm}$. - Fig. 4 . A single juvenile E. globulus tree observed to produce kino vein in both xylem (4A) and phloem (4B). 
This initial wound response was similar to the wound healing response observed in other tree species such as conifers (Kuroda \& Shimaji 1984) and other hardwood species (Lev-Yadun \& Aloni 1995). The differentiation of ray parenchyma is an important process in wound regeneration as callus produced from ray cells then has the potential to develop into a new cambium (Kozlowski \& Pallardy 1997). In addition, ray parenchyma cells are responsible for the synthesis of various phenolic compounds (Shortle 1979) and are the source of tyloses and polysaccharide deposits in vessels (Chattaway 1949).

\section{Response of E. globulus and E. obliqua to CEPA treatment}

Macroscopic observations - Kino veins were induced in juvenile E. globulus and E. obliqua by the CEPA treatment (Table 1). The rate of kino vein development observed for E. globulus was generally slower compared to that for E. obliqua. Kino was observed to exude onto the bark surface after approximately 14 days in E. obliqua and 28 days in E. globulus. The kino was initially a sticky straw-coloured exudate that upon exposure to air polymerized to become brittle, assuming a cherry red to brown/black colour.

Table 1. Response of Eucalyptus globulus, E. obliqua and E. nitens to treatments.

\begin{tabular}{lcc}
\hline Species & \multicolumn{2}{c}{$\%$ Kino veins induced } \\
\cline { 2 - 3 } & CEPA treament & Control treatment \\
\hline E. globulus & 100 & 0 \\
E. obliqua & 100 & 30 \\
E. nitens & 0 & 0 \\
\hline
\end{tabular}

The induced kino veins were mostly included in the phloem of E. globulus and in the xylem of E. obliqua (Fig. 3). Anatomical work carried out by Day (1959) found evidence to suggest that location of kino veins, i.e. whether kino veins are found in either the xylem or phloem, may be species dependent. Moreover, a survey of 93 Eucalyptus species (based on Pryor and Johnson's classification system, 1971) determined that species that exhibit kino veins in the xylem belong to the subgenera Monocalyptus and Corymbia. Species observed to develop kino veins in the phloem were all members of three sections of subgenus Symphyomyrtus (Tippett 1986). Therefore, according to Tippett, kino veins should be induced in xylem of E. globulus and E. obliqua. In this study, kino veins were always induced in the xylem of E. obliqua; however, kino veins were mostly found in the phloem of E. globulus.

\footnotetext{
$\leftarrow$

Location of insect borer found in square. Scale bars approximately $0.5 \mathrm{~cm} .-\mathrm{CZ}=$ cambial zone; $\mathrm{IW}=$ initial wound; $\mathrm{KV}=$ kino vein; $\mathrm{P}=$ phloem; $\mathrm{RP}=$ ray parenchyma; $\mathrm{RS}=$ ray swell; $\mathrm{X}=$ xylem.
} 

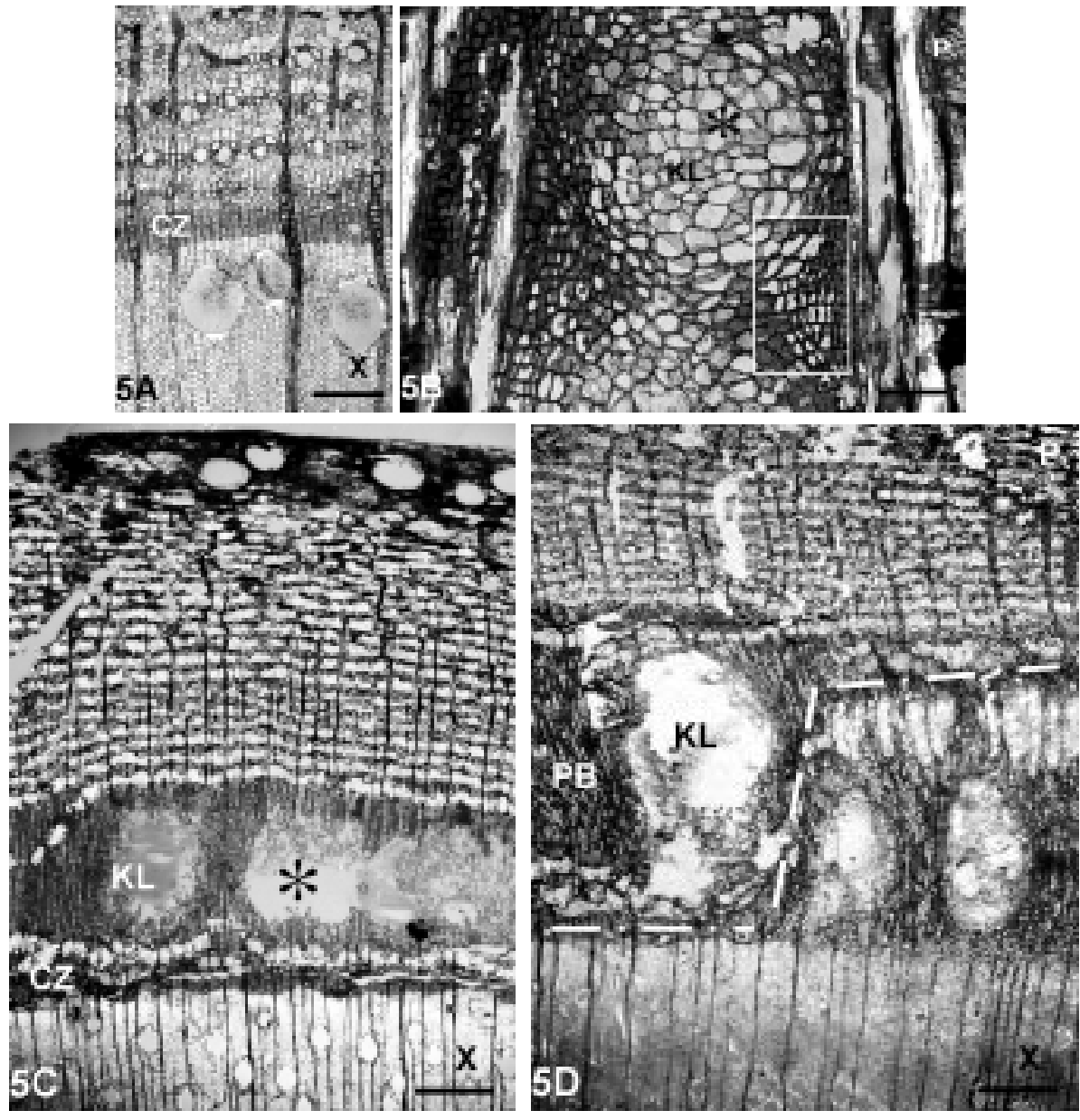

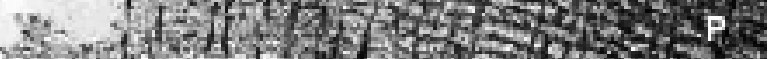

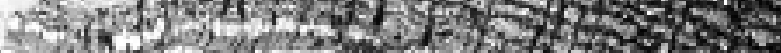

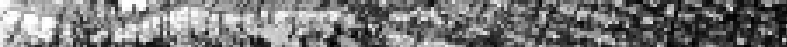
fich of

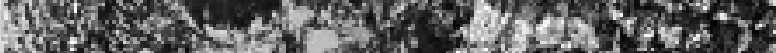

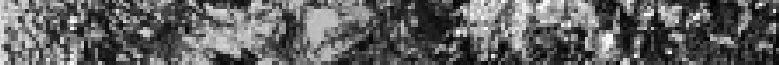

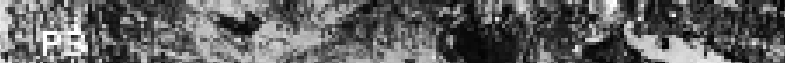

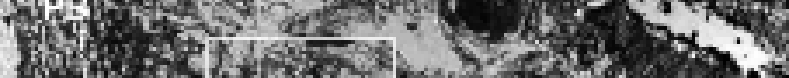
130 . NW

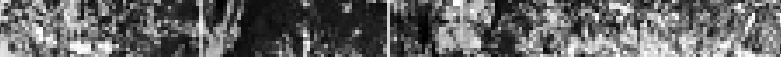

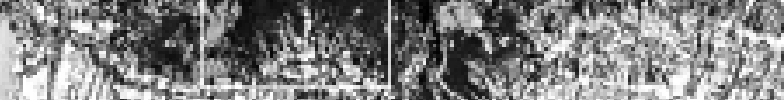

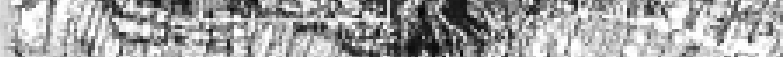

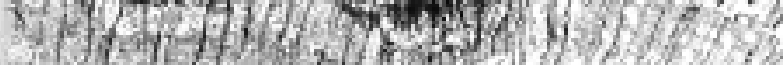

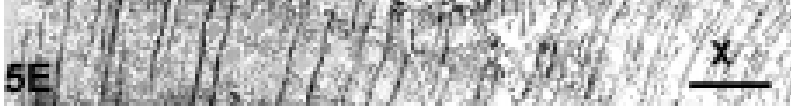


Juvenile E. globulus may have the potential to produce kino veins, which may be included in either phloem or xylem depending on the nature of the injury. For example, a single E. globulus tree exhibited kino veins in the phloem and in the xylem at two different locations along the bole (Fig. 4). The distinct but separate kino veins located in the phloem were associated with insect borer attack while the kino veins located in the xylem appeared to be associated with fungal decay. Alternatively, tree maturity may influence the location of kino veins. In nature, injury to eucalypt trees less than 4 to 5 years of age rarely results in kino vein formation (Dowden \& Foster 1973). Likewise, Acacia senegal needs to be 5-7 years of age before it is able to produce gum (Joseleau \& Ullmann 1990) suggesting that juvenile trees respond differently to wounding compared to mature trees. Evidence to support this alternative explanation can be found in this study. In the first year of the experiment when 2-year-old E. globulus trees were used, kino veins were always induced in the phloem following treatment with CEPA. But in the second year of the experiment, when 3 -year-old E. globulus trees were used, it was difficult to determine from the anatomical sections whether the kino veins were induced in the phloem or xylem (Fig. 5D). In one area of the sections, the kino veins appear to be included in the phloem while in another area of the same section, the kino veins appear to be included in the xylem (Fig. 5D).

\section{Response of E. nitens to CEPA treatment}

Kino veins were not induced in juvenile E. nitens (Table 1) by CEPA treatment suggesting that this species does not readily form kino veins (Yang \& Waugh 1996). Even mature E. nitens trees treated with CEPA generally failed to induce kino vein formation (Eyles, personal observation). Instead, longitudinal sections of E. nitens 28 days after CEPA treatment revealed the production of around eight to ten tangential rows of a combination of apotracheal parenchyma and enlarged ray parenchyma. This response was clearly different to that observed in the control. After 4 weeks, the wood was observed to be coloured a distinct pink. The pink-coloured wood was treated with BBG-250. Fresh sections stained intensely blue indicating the presence of hydrolyzable tannins in this tissue (Fig. 6B). Resumption of normal wood production by the cambium occurred 35 days after CEPA treatment.

Fig. 5. Transverse (A, C-E) and radial longitudinal (B) sections showing kino vein development in E. globulus. - A: Control. Scale bar $=200 \mu \mathrm{m}$. $-\mathrm{B}$ : Expanded thin-walled traumatic parenchyma $(*)$ observed 21 days post-induction. Prominent nuclei in the newly differentiated cells are located in the square. Scale bar $=150 \mu \mathrm{m} .-\mathrm{C}$ : Disintegration of the central cells $(*)$ within the kino lacunae observed 28 days post-induction. Scale bar $=500 \mu \mathrm{m}$. $-\mathrm{D}$ : Mature kino vein 35 days post-induction. The orientation of the vascular cambium (broken line) changes so that the kino vein appears to be included in both xylem and phloem. Scale bar $=500 \mu \mathrm{m}$. E: Example of complex kino vein anatomy 35 days post-induction. Hemispherical protuberances formed on the outer edge of kino lacuna are located in the square. Scale bar $=500 \mu \mathrm{m}$. $-\mathrm{CZ}$ = cambial zone; $\mathrm{KL}=$ kino lacuna $\mathrm{P}=$ phloem $\mathrm{PB}=$ parenchyma bridge; $\mathrm{PF}=$ phloem fibres; $\mathrm{X}=$ xylem. 


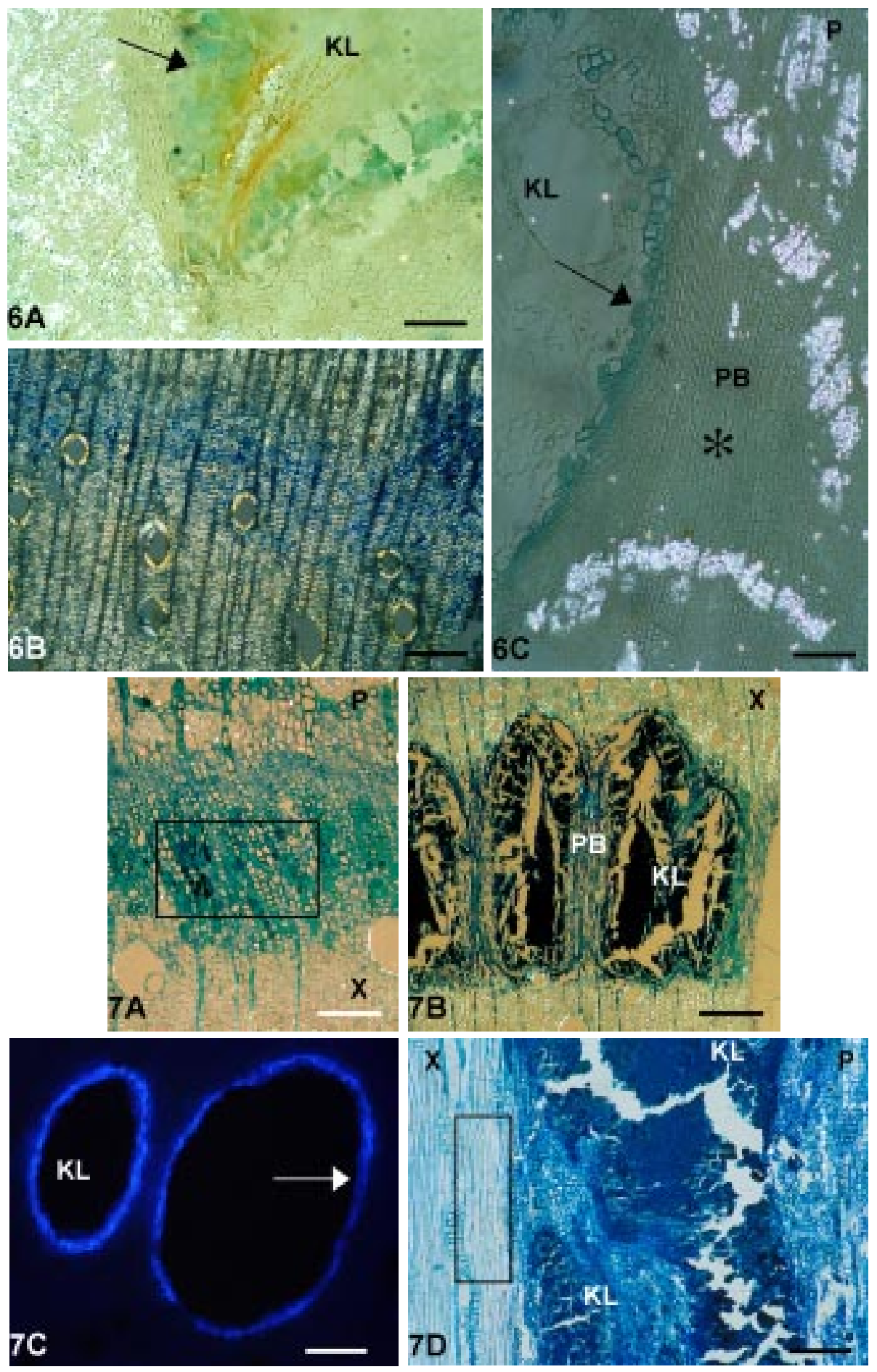


The axial-like parenchyma and ray-like parenchyma tissue cells produced by juvenile $E$. nitens in response to CEPA treatment is very similar to the barrier zones formed in response to wounding and infection in other tree species such as beech (Fagus sylvatica) (Torelli et al. 1994). Here, abnormally large amounts of axial parenchyma characterized the barrier zone.

\section{Kino vein development in E. globulus and E. obliqua}

Approximately 7-14 days after CEPA treatment, the cambial initials had undergone rapid tangential and transverse division, producing broad bands of isodiametric thin-walled traumatic parenchyma cells. The central parenchyma cells accumulated polyphenols (Fig. 7A) and appeared to expand up to four times their original size. Subsequently these cells collapsed, most likely via a schizo-lysigenous process, to form the kino lacunae (Fig. 6C \& 7B). Tissue described as 'parenchyma bridges' developed between the lacunae. The parenchyma bridge consisted of thin-walled radially elongated brick-like cells often containing occasional crystalliferous parenchyma and phloem fibre-like cells (Fig. 6E \& 7B). The parenchyma bridges tested negative for the presence of proanthocyanidins, indicating that these parenchyma bridges have no role in the synthesis of polyphenols (Fig. 6C). Instead, the production of parenchyma bridges may serve to ensure the survival of the vascular cambium by forming a living link of cells between the xylem on either side of the tangential row of cavities, particularly since reversion to normal wood formation starts in the bridge tissue. During kino vein formation, the ray parenchyma remained intact if found within a wide parenchyma bridge. However, if the ray parenchyma was within the lacuna at the time of tissue differentiation, the ray cambial cells also produced traumatic parenchyma, similarly to that observed by Dowden and Foster (1973) in E. radiata. The two to four cell deep layer of parenchyma surrounding the lacuna became suberized approximately 5 weeks after treatment for E. obliqua and approximately 7 weeks for E. globulus. In comparison, Skene (1965) studying kino vein formation in mature E. obliqua, noted the production of suberized cells 7-8 weeks after wounding with a saw. The presence of suberized cells was successfully detected by Sudan black B dye and fur-

Fig. 6. Localization of phenolic compounds with Coomassie BBG-250 and DMACA stains.A \& C: Transverse section showing the concentric cells (arrows) lining the kino vein of $E$. globulus staining positive with DMACA treatment, 35 days post-induction. No reaction observed in the parenchyma bridge $\left(^{*}\right)$. Scale bar $=150 \mu \mathrm{m}$. - B: Transverse section showing localization of hydrolyzable tannins in the barrier zone of E. nitens 49 days post induction with the Coomassie stain. Scale bar $=150 \mu \mathrm{m}$. - Fig. 7. Transverse $(\mathrm{A}-\mathrm{C})$ and radial longitudinal (D) section showing kino vein development in E. obliqua. - A: Traumatic parenchyma produced by vascular cambium is observed to accumulate polyphenolic extractives (*) 14 days post-induction. Scale bar $=150 \mu \mathrm{m}$. - B: Mature kino vein in xylem 35 days post-induction. Scale bar $=200 \mu \mathrm{m}$. - C: Suberized cells (arrow) lining mature kino vein 42 days postinduction. Scale bar $=200 \mu \mathrm{m}$. - D: High number of axial parenchyma (square) along the pith side of kino vein observed 42 days post-induction. Scale bar $=150 \mu \mathrm{m} .-\mathrm{KL}=$ kino lacuna; $\mathrm{P}=$ phloem $; \mathrm{PB}=$ parenchyma bridge $; \mathrm{X}=$ xylem . 
ther confirmed by both fluorescence microscopy (Fig. 7C). The cambium resumes normal xylem formation following suberization of these cells.

In E. globulus trees only, the parenchyma cells at the outer edge of the kino lacuna underwent multiple divisions to produce concentric layers of epithelial cells that appeared to secrete kino into their vacuoles (Fig. 5E). Evidence of these specialized kino-secreting cells was provided by the DMACA test, which detected the presence of proanthocyanidins only in these cells (Fig. 6A \& C). The innermost layer of cells lining the lacuna became greatly extended, subsequently crushing the thin-walled cells located at the centre of the lacuna (Fig. 6A). The continuous division of the meristematic layer surrounding the lacuna then appeared to replace those compressed cells. The developing kino-forming cells were characterized by their large nuclei (Fig. 5B).

The ability of the parenchyma cells surrounding the lacuna to become meristematic and appear cambiform was likewise observed by Babu et al. (1987) in their study of the development of traumatic gum-resin cavities in the xylem of Ailanthus excelsa. The workers suggest the adjacent meristematic cambiform cells contribute to the gumresin formation by providing additional epithelial cells particularly during prolonged exudation. Based on our observations, the more complex description of kino vein formation as detailed above can also provide a possible mechanism to explain cases of prolonged kino production in the plant. Moreover, in some kino veins, the area of kino secreting tissues was increased by the formation of hemispherical or elongate protuberances on the outer edge of the lacuna (Fig. 5E). This latter anatomical feature was also observed by Dowden and Foster (1973).

The general structure of individual kino veins found in both E. globulus and $E$. obliqua appears to resemble those described in other eucalypt species, e.g. E. camaldulensis and E. gomphocephala (Day 1959), E. obliqua (Skene 1965), E. radiata (Dowden \& Foster 1973), E. wandoo and E. marginata (Tippett 1986). However, one anatomical feature only briefly mentioned by Tippett et al. (1983), but commonly observed in this study, was the presence of three to six tangential rows of axial parenchyma located on the pith side of the mature kino vein in both E. globulus and $E$. obliqua (Fig. 7D). As mentioned earlier for E. nitens, the increased production of axial parenchyma has often been characterized as part of the barrier zone wound response by many tree species (Tippett \& Shigo 1981; Shigo 1984). Tippet and Shigo (1981) suggest that the living nature of barrier zones allows this specialized tissue to actively respond against injury and infection by a range of defence mechanisms such as production of polyphenols.

\section{ORIGIN OF TRAUMATIC PARENCHYMA}

The origin of traumatic secretory structures induced in both the xylem and phloem of other tree species has been studied. For example, traumatic resin canals induced in the xylem of Abies firma are derived from xylem mother cells (Kuroda \& Shimaji 1984). This study showed that in E. obliqua trees, the traumatic parenchyma, which later develops into kino veins and then becomes included in the xylem, similarly orig- 
inates from the vascular cambium (Fig. 7A). In contrast, traumatic resin canals formed in the phloem of Japanese cypress (Chamaecyparis obtusa), are derived not from phloem mother cells but from a tangential band of parenchyma cells located in close proximity to the vascular cambium (Yamanaka 1989). The derivation of traumatic parenchyma in E. globulus was similar to that observed C. obtusa, i. e. the kino veins that were induced in the phloem of juvenile E. globulus did not appear to originate from the vascular cambium but instead appeared to be derived from the meristematic activity of the phloem parenchyma (Fig. 5B \& C). More specifically, kino vein development began with the radial proliferation of 20-30 cells of traumatic parenchyma in the first layer of the phloem parenchyma cells adjacent to the xylem while the vascular cambium remains intact, as a continuous layer (Fig. 5C). These results are in conflict with the findings reported by Tippett (1986) who studied the development of artificially induced kino veins in mature E. marginata and E. wandoo. Tippett concluded that the traumatic parenchyma originated from the vascular cambium, regardless of whether the kino veins became included in the phloem or xylem. The differentiation of 'phloem' fibres within the bands of the parenchyma was only briefly noted. In an attempt to clarify the role of phloem parenchyma in the production of kino veins induced in the phloem, future work may involve studying kino vein development in Eucalyptus species that induce kino veins in phloem only.

\section{ACKNOWLEDGEMENTS}

The authors would like to thank Dr Ted Hillis for discussions during the development of the study and Drs Matthew Leitch, Keiko Kuroda, Geoff Downes and Chris Beadle for providing helpful comments and constructive criticisms during the revision of the manuscript.

\section{REFERENCES}

Babu, A.M., G.M. Nair \& J. J. Shah. 1987. Traumatic gum-resin cavities in the stem of Ailanthus excelsa Roxb. IAWA Bull. n.s. 8: 167-174.

Bamber, R.K. 1985. The wood anatomy of eucalypts and papermaking. Appita J. 38: 210-216. Beadle, C. \& C. Mohammed. 1999. Pruning for plantation sawlogs. Onwood Research Updates No. 24. CSIRO Forestry and Forestry Products.

Biggs, A.R. 1984. Occurrence and location of suberin in wound reaction zones in xylem of 17 tree species. Phytopathology 77: 718-725.

Chattaway, M.M. 1949. The development of tyloses and secretion of gum in heartwood formation. Aust. J. Sci. Res. Ser. B2, 3: 227-240.

Day, W.R. 1959. Observations of eucalypts in Cyprus; the character of gum veins and anatomical indications for their origin. Empire Forest Rev. 38: 35-44.

Dowden, H. \& R.C. Foster. 1973. Kino veins, their formation, anatomy and fine structure. Proc. $16^{\text {th }}$ Forest Products Conf., CSIRO: 1-5.

Gerrand, A.M., W.A. Neilsen \& J.L. Medhurst. 1997. Thinning and pruning eucalypt plantations for sawlog production in Tasmania. Tasforests 9: 15-33.

Gutmann, M. 1993. Localization of proanthocyanidins using in situ-hydrolysis with sulphuric acid. Biotech. Histochem. 68: 161-165.

Hillis, W.E. 1975. Ethylene and extraneous material formation in woody tissues. Phytochemistry $14: 2559-2562$. 
Hillis, W.E. 1987. Heartwood and tree exudates. Springer-Verlag, Berlin. 268 pp.

Hillis, W.E. \& Y. Yazaki. 1975. Kinos of Eucalyptus species and their acid degradation products. Phytochemistry 13: 495-498.

Jensen, W.A. 1962. Botanical histochemistry; principles and practice. W.H. Freeman \& Co., San Francisco, London. 408 pp.

Joseleau, J. \& G. Ullmann. 1990. Biochemical evidence for the site of formation of gum arabic in Acacia senegal. 29: 340-345.

Kilkowski, W. J. \& G.G. Gross. 1999. Color reaction of hydrolyzable tannins with Bradford reagent, Coomassie brilliant blue. Phytochemistry 51: 363-366.

Kozlowski, T. T. \& S.G. Pallardy. 1997. Growth control in woody plants. Academic Press, San Diego. 641 pp.

Kuroda, K. \& K. Shimaji. 1984. Wound effects on xylem cell differentiation in a conifer. IAWA Bull. n.s. 5: 295-305.

Lev-Yadun, S. \& R. Aloni. 1995. Differentiation of the ray system in woody plants. Bot. Rev. 61: 45-84.

Pryor, L.D \& L.A.S. Johnson. 1971. A classification of the eucalypts. Aust. Nat. Univ., Canberra. $102 \mathrm{pp}$.

Shigo, A.L. 1984. Compartmentalization: a conceptual framework for understanding how trees grow and defend themselves. Ann. Rev. Phytopathol. 22: 189-214.

Shortle, W.C. 1979. Mechanisms of compartmentalization of decay in living trees. Phytopathology 69: 1147-1151.

Skene, D.S. 1965. The development of kino veins in Eucalyptus obliqua L'Hérit. Aust. J. Bot. 13: 367-378.

Tippett, J.T. 1986. Formation and fate of kino veins in Eucalyptus L'Hérit. IAWA Bull. n. s. 7: 137-143.

Tippett, J. T. \& A.L. Shigo. 1981. Barrier zone formation: a mechanism of tree defense against vascular pathogens. IAWA Bull. n.s. 2: 163-168.

Tippett, J.T., S.R. Shea, T.C Hill \& B.L. Shearer. 1983. Development of lesions caused by Phytophthora cinnamomi in the secondary phloem of Eucalyptus marginata. Aust. J. Bot. 31: $197-210$.

Torelli, N., B. Krizaj \& P. Oven. 1994. Barrier zone (CODIT) and wound-associated wood in beech (Fagus sylvatica L.). Holzforsch. Holzverw. 3: 49-51.

Yang, J.L. \& G. Waugh. 1996. Potential of plantation-grown eucalypts for structural sawn products. II. Eucalyptus nitens (Dean \& Maiden) Maiden and E. regnans F. Muell. Aust. Forestry 59: 99-107.

Yamanaka, K. 1989. Formation of traumatic phloem resin canals in Chamaecyparis obtusa. IAWA Bull. n.s. 10: 4384-4394. 


\section{IAWA Journal - Reprint price information and Order form}

The standard price of IAWA Journal reprints is in American dollars USD 8.00 per 50 copies of each article page. Reprints may be ordered at a minimum number of 50 , or a multiple thereof. The editors regret that no reprints can be provided free of charge.

Your manuscript covers 12 IAWA Journal pages = USD 96.00 per 50 copies. Please complete the order form below and return this information together with the proof corrections by e-mail, fax, or postal mail. Extra costs for the colour plate on p. $426=$ USD 390.

We have to charge you directly for the costs of mailing the reprints to your address. These costs (standard mail) will depend on the weight of the parcel and will be mentioned on the invoice in addition to the price of the reprints.

\section{ORDER FORM}

$\square$ Reprints not required

$\square$ Number of reprints ordered:

Title of paper :

Author(s) :

Name and address to whom the invoice should be sent :

Name and address to whom the reprints should be shipped: 